\title{
PEGADA CARBONO DE ÓRGÃOS PÚBLICOS: GUIA DE CÁLCULO BASEADO NA APLICAÇÃO DO BOOKFEEL NO MINISTÉRIO PÚBLICO DO ESTADO DA BAHIA/ BRASIL
}

\author{
Thiago Alexs andro Novaes das Virgens \\ Doutorando em Engenharia Industrial \\ Universidade Federal da Bahia Salvador - BA - Brasil \\ thiagodasvirgens@gmail.com https://orcid.org/0000-0003-2120-0733 \\ José Célio Silveira Andrade \\ Doutor em Administração \\ Universidade Federal da Bahia Salvador - BA - Brasil \\ celiosa@ufba.br \\ Sebas tián Labella Hidalgo \\ Fundación para la Cooperación Internacional Barcelona-ES \\ sebastian.labella@carbonfeel.org
}

\begin{abstract}
RESUMO
O GHG Protocol se tornou o método mais utilizado no mundo para calcular as emissões de Gases de Efeito Estufa (GEE) nas organizações. No entanto, há um baixo reconhecimento das emissões de Escopo 3, seja por ser de caráter voluntário seja por apresentar dificuldades técnicas para calcular essas emissões. Devido ao fato de os órgãos públicos executarem maiormente serviços e consumir bens e serviços, o Escopo 3 é relevante e demanda adoção de método/ ferramenta de cálculo que facilitem estimá-lo. Neste sentido, este trabalho objetiva, de forma pioneira e inovadora, descrever os principais passos executados para calcular a Pegada de Carbono do Ministério Público da Bahia (MPBA)/ Brasil, no ano-base 2017, apresentar e validar, para o contexto brasileiro, a ferramenta de cálculo "BookFeel", baseada no Método Composto pelas Contas Contábeis (MC3), evidenciando suas potencialidades e limitações e propor um guia para calcular a PC em órgãos públicos. Os resultados constataram que o BookFeel é uma ferramenta válida, flexível, fácil de usar e capaz de calcular a PC com amplo Escopo 3, respeitando as diretrizes do Ipcc, GHG Protocol e ISO 14064, tendo importantes diferenciais, entre eles: geração de gráficos na própria ferramenta; rastreabilidade de informações; cálculo de forma colaborativa e, principalmente, inserção de unidades monetárias, que viabilizam calcular a PC em organizações que não dispõem de informações sobre o consumo de bens e serviços expressos em unidades físicas. Preenchendo parte da lacuna existente, esta pesquisa lança luz para a necessidade e para uma forma viável de calcular a PC em órgãos públicos.
\end{abstract}

Palavras-chave: BookFeel. Ferramenta de cálculo. GEE. GHG protocol. MC3.

\section{PUBLIC AGENCY CARBON FOOTPRINT: CALCULATION GUIDE BASED ON BOOKFEEL APPLICATION IN THE PROSECUTION SERVICE OF THE STATE OF BAHIA/ BRAZIL}

\section{ABSTRACT}

The GHG Protocol has become the most widely used method in the world for calculating Greenhouse Gas (GHG) emissions in organizations. However, there is low recognition of Scope 3 emissions, either because it is voluntary or has technical difficulties in calculating these emissions. Because public agencies mostly perform services and consume goods and services, Scope 3 is relevant and requires the adoption of a calculation method/tool that makes it easier to estimate it. In this sense, this work aims, in a pioneering and innovative way, to present the main steps of calculating the Carbon Footprint (CF) of the Prosecution Service of the State of Bahia/ Brazil, in the base year 2017, to present and validate for the Brazilian context the calculation tool "BookFeel", based on the Accounting Compound Method (MC3), highlighting its potentials and limitations and to propose a guide for the calculation of $\mathrm{CF}$ in public agenc ies. The results found that BookFeel is a valid, flexible, easy-to-use tool capable of calculating broad Scope $3 \mathrm{CF}$, respecting the Ipcc, GHG Protocol and ISO 14064 guidelines, with important differences, including: graphics generation in the tool itself; traceability of information; calculating in a collaborative way and, mainly, insertion of currency units, which makes it possible to calculate the CF in organizations that do not have information on the consumption of goods and services expressed in physical units. Filling part of the existing gap, this research sheds light on the need and a viable way to calculate $\mathrm{CF}$ in public agencies.

Key words: BookFeel. Calculation tool. GHG. GHG protocol. MC3.

Data da submissão: $25 / 12 / 2019$

Data de aceite: $05 / 02 / 2020$ 


\section{INTRODUÇÃO}

A gestão por uma menor Pegada de Carbono (PC) nas organizações demanda a execução do cálculo das emissões dos Gases de Efeito Estufa (GEE), assim como a adoção de práticas sustentáveis direcionadas para redução, mitigação e compensação de forma sistemática da PC. Assim, é cada vez maior o número de organizações comprometidas com ações climáticas, especialmente, em razão do Acordo de Paris. Para López et al. (2019), os agentes públicos e estatais têm que estabelecer compromissos fortes na luta contra a mudança climática. Neste sentido, considerando as influências políticas, sociais e econômicas, os serviços ofertados, o poder de regulamentação e fiscalização e, especialmente, o elevado poder de consumo de bens e serviços, os órgãos públicos são importantes players no combate às mudanças do clima. Apesar disto, não se tem conhecimento de órgãos públicos brasileiros que reconheçam, mitiguem e/ou compensem suas PCs de forma sistemática.

Considerando a definição dos escopos do GHG Protocol, a situação é ainda pior quando se considera o cálculo das emissões de Escopo 3, as quais resultam das atividades da organização, mas ocorrem em fontes não pertencentes ou controladas por ela. Calcular o Escopo 3 é mais trabalhoso, difícil e demanda uma abordagem baseada no consumo, inclusive com a adoção de indicadores financeiros. Com isto, boa parte das organizações não considera esse escopo ou o calcula parcialmente, mesmo porque o seu reporte não é obrigatório (Hoekstra e Wiedmann, 2014; OzawaMeida et al., 2013). Todavia, dada a natureza das atividades dos órgãos públicos, as emissões de Escopo 3 tendem a concentrar as maiores emissões.

Têm-se diferentes métodos para calcular PC Organizacional, destacando-se a ISO 14064-1 e o GHG Protocol, método mais utilizado no mundo, inclusive no Brasil, enquanto para calcular a PC de Produto, têm-se a ISO 14067 e PAS 2050 (Gvces, 2019; ISO, 2006; Wbcsd e WRI, 2004). Já, nos anos 2000, foram desenvolvidos e validados, na Espanha, o Método Composto das Contas Contábeis (MC3, acrônimo do espanhol "Método Compuesto de las Cuentas Contables") e a ferramenta de cálculo BookFeel, capazes de calcular a PC organizacional e de produtos, de forma simultânea e sensíveis, para calcular o consumo de bens e serviços, principalmente por também considerar indicadores financeiros em seus algoritmos de cálculo, o que pode ser essencial para organizações que não dispõem de informações sobre determinados consumos em unidades físicas, mas em despesas financeiras (Veiga, 2017).

Diante do exposto, este trabalho objetiva descrever os principais passos executados para calcular a Pegada de Carbono do Ministério Público da Bahia (Mpba), no ano-base 2017, apresentar e validar para o contexto brasileiro a ferramenta de cálculo BookFeel, evidenciando suas potencialidades e limitações e propor um guia para calcular a PC em órgãos públicos. Com isto, este trabalho é pioneiro e inovador por enforcar no cálculo das emissões de Escopo 3 de órgãos públicos, incluindo o consumo de bens e serviços. Pelos estudos realizados, é a primeira vez que um trabalho se esforça em propor um guia para calcular a PC de órgãos públicos, especialmente para os localizados na América Latina, preenchendo parte da lacuna existente, já que a maior parte das pesquisas realizadas se concentra na $\mathrm{PC}$ de organizações privadas. Por conveniente, considerandose que o detalhamento da PC do Mpba não é um dos objetivos deste trabalho, ele pode ser visto em Virgens et al. (2020).

\subsection{Pegada de carbono organizacional: principais metodologias}

A PC pode ser entendida como a contabilização dos GEE que, direta e indiretamente, foram emitidos por atividades, serviços e/ou produtos, considerando os limites espaciais e temporais especificados (Peters, 2010; Schaltegger e Csutora, 2012). A PC pode ser calculada com diferentes métodos e abordagens e, normalmente, as metodologias para o cálculo se subdividem em PC Organizacional e PC de Produtos. Na primeira, tem-se a medição de todos os GEE emitidos por 
Thiago Alexsandro Novaes das Virgens, José Célio Silveira Andrade, Sebastián Labella Hidalgo

efeito direto ou indireto a partir do desenvolvimento das atividades de uma referida organização em um período. Neste caso, destacam-se a ISO 14.064-1 e o GHG Protocol, que foram baseadas nas diretrizes para a elaboração dos inventários nacionais do Intergovernmental Panel on Climate Change (Ipcc), de 1996 e 2006. Já, para calcular a PC de Produto, a qual mede o GEE emitido durante todo o ciclo de vida de um produto, desde a extração de matérias-primas, passando pelo processamento, fabricação e distribuição, até o uso e fim da vida útil, destacam-se a ISO 14.067 e o PAS 2050, que abarcaram as diretrizes da Avaliação do Ciclo de Vida (ACV) (Álvarez et al., 2014; European Commission, 2004; ISO, 2006; Wbcsd e WRI, 2004). A figura 1, a seguir, lista as principais metodologias de cálculo da PC no mundo.

\begin{tabular}{|c|c|c|}
\hline Metodologia & Âmbito de Aplicação & Enfoque \\
\hline Carbon Disclosure Project (CDP) & Aplicação voluntária e global. Amplamente adotada. & \multirow{8}{*}{ 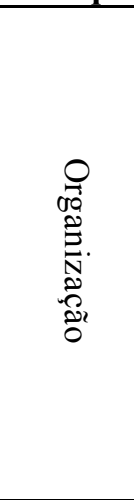 } \\
\hline ISO 14.064-1 & $\begin{array}{c}\text { Aplicação voluntária e global. Padrão internacional } \\
\text { verificável }\end{array}$ & \\
\hline Wbcsd/WRI GHG Protocol & $\begin{array}{c}\text { Aplicação voluntária e global. Serviu de base para } \\
\text { outros padrões. }\end{array}$ & \\
\hline $\begin{array}{l}\text { Método Compuesto de las Cuentas } \\
\text { Contables (MC3) }\end{array}$ & $\begin{array}{l}\text { Aplicação voluntária e amplamente reconhecida na } \\
\text { Espanha, especialmente, para o cálculo do Escopo } 3 .\end{array}$ & \\
\hline French Bilan Carbone & Aplicação voluntária e aplicada na Europa. & \\
\hline Defra Company GHG Guidance & Aplicação voluntária e aplicada na Europa. & \\
\hline GHG Protocol for Cities (GPC) & $\begin{array}{l}\text { Aplicação voluntária e global. Amplamente } \\
\text { reconhecida para calcular as emissões em cidades. }\end{array}$ & \\
\hline US GHG Protocol Public Sector Standard & Aplicação voluntária e aplicada nos EUA. & \\
\hline $\begin{array}{l}\text { GHG Protocol - Product Life Cycle } \\
\text { Accounting and Reporting Standard }\end{array}$ & Aplicação voluntária e global. & \multirow{7}{*}{ 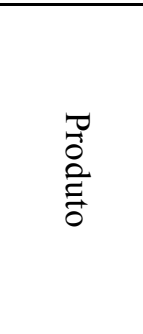 } \\
\hline ISO 14.067 & Aplicação voluntária e global. & \\
\hline Carbon Footprint Program & Aplicação voluntária e desenvolvida no Japão. & \\
\hline Carbon Index Casino & Aplicação voluntária e desenvolvida na França. & \\
\hline Climate Certification System & Aplicação voluntária e desenvolvida na Suécia. & \\
\hline Climatop & Aplicação voluntária e desenvolvida na Suíça. & \\
\hline$B P X 30-323$ & Aplicação voluntária e desenvolvida na França. & \\
\hline
\end{tabular}

Figura 1. Principais metodologias de cálculo de Pegada de Carbono utilizadas no mundo

Fonte: Adaptado de Herrero et al. (2011); Andrade et al. (2018); Faria et al. (2018); ISO (2006); Wbcsd (2004)

Consoante com levantamento realizado no Scopus, Web Of Science e Google Scholar, foram identificadas parcas publicações sobre cálculo e gestão da PC em órgãos públicos. A maior parte dos estudos busca estimar a PC de entes privados ou de produtos (Álvarez et al., 2019, 2015, 2014; Arellano-wences et al., 2015; Cagiao et al., 2011; Carballo-Penela e Doménech, 2010; Correa et al., 2019; Gui et al., 2019; López et al., 2019; Penz e Polsa, 2018; Pereira et al., 2016) e, quando o foco passa a ser entes públicos, os estudos abarcam universidades, cidades, estados e países (Abdullah et al., 2019; Barrett et al., 2013; Chen et al., 2016; Fry et al., 2018; Larsen et al., 2013; Lombardi et al., 2018; Markolf et al., 2017; Miehe et al., 2016; Robinson et al., 2018; Wiedmann e Barrett, 2011). A figura 2 apresenta os principais estudos realizados sobre PC Organizacional, cujo maior detalhamento dos resultados podem ser obtidos em Virgens et al. (2020).

\begin{tabular}{|c|c|c|c|c|c|}
\hline Autor & Unidade inventariada & Tipo & Método & Ano & Escopos \\
\hline Miteco (2018) & $\begin{array}{c}\text { Ministério da Agricultura e Pesca, } \\
\text { Alimentação e Meio Ambiente } \\
\text { (Mapama), Espanha }\end{array}$ & Público & $\begin{array}{c}\text { GHG } \\
\text { Protocol }\end{array}$ & 2016 & 1,2 e 3 \\
\hline CPS (2018) & $\begin{array}{c}\text { Crown Prosecution Service, Reino } \\
\text { Unido }\end{array}$ & Público & $\begin{array}{c}\text { Não } \\
\text { informado }\end{array}$ & 2017 & 1,2 e 3 \\
\hline DPF (2017) & $\begin{array}{c}\text { Matriz da Polícia Federal do Brasil } \\
\text { (DPF), Brasil }\end{array}$ & Público & $\begin{array}{c}\text { GHG } \\
\text { Protocol }\end{array}$ & 2017 & 1,2 e 3 \\
\hline Veiga (2017) & DTS S.A. (Construção Civil), & Privada & MC3 & 2015 & 1,2 e 3 \\
\hline
\end{tabular}

Revista de Gestão Social e Ambiental - RGSA, São Paulo, v. 14, n. 1, p. 74-92, jan./abr. 2020. 
Pegada carbono de órgãos públicos: guia de cálculo baseado na aplicação do Bookfeel no ministério público do estado da Bahia/Brasil

\begin{tabular}{|c|c|c|c|c|c|}
\hline $\begin{array}{c}\text { Vásquez et al. } \\
(2015)\end{array}$ & $\begin{array}{c}\text { Campus de Curico, Universidade de } \\
\text { Talca, Chile }\end{array}$ & Pública & $\begin{array}{c}\text { GHG } \\
\text { Protocol }\end{array}$ & 2012 & 1,2 e 3 \\
\hline $\begin{array}{c}\text { Álvarez e } \\
\text { Rubio (2015a) }\end{array}$ & $\begin{array}{c}\text { Serviço de Conservação e } \\
\text { Manutenção Terceirizada, Espanha }\end{array}$ & Privada & MC3 & $\begin{array}{c}2011 \\
2012\end{array}$ & 1,2 e 3 \\
\hline $\begin{array}{c}\text { Álvarez et al. } \\
(2014)\end{array}$ & $\begin{array}{c}\text { Escola de Engenharia Florestal, } \\
\text { Universidade Técnica de Madrid, } \\
\text { Espanha }\end{array}$ & Privada & MC3 & 2010 & 1,2 e 3 \\
\hline $\begin{array}{c}\text { Lima et al } \\
(2014)\end{array}$ & $\begin{array}{c}\text { Empresa Brasileira de Pesquisa } \\
\text { Agropecuária (Embrapa), Unidade } \\
\text { Hortaliças, Brasil }\end{array}$ & Pública & $\begin{array}{c}\text { GHG } \\
\text { Protocol }\end{array}$ & 2012 & 1,2 e 3 \\
\hline $\begin{array}{c}\text { Santos et al. } \\
(2015)\end{array}$ & $\begin{array}{c}\text { Empresa Baiana de Água e } \\
\text { Saneamento S.A. (Embasa), Brasil }\end{array}$ & Pública & $\begin{array}{c}\text { GHG } \\
\text { Protocol }\end{array}$ & 2012 & 1,2 e 3 \\
\hline $\begin{array}{c}\text { Santa Catarina } \\
(2012)\end{array}$ & $\begin{array}{c}\text { Governo de Estado de Santa Catarina } \\
\text { (Gesc) }\end{array}$ & Pública & $\begin{array}{c}\text { GHG } \\
\text { Protocol }\end{array}$ & 2012 & 1,2 e 3 \\
\hline
\end{tabular}

Figura 2. Principais estudos identificados sobre o cálculo da Pegada de Carbono Organizacional Fonte: Adaptado de Virgens et al. (2020)

A seguir, tendo em vista os objetivos deste trabalho, será dado enfoque nas metodologias ISO 14.064 e GHG Protocol, por serem as mais utilizadas para calcular a PC Organizacional e, posteriormente, no MC3, por ter sido a metodologia adotada neste trabalho.

\subsection{ISO 14.064 e GHG Protocol}

A ISO 14.064 é dividida em três partes, sendo que no Brasil foi publicada pela Associação Brasileira de Normas Técnicas (Abnt) por meio das Abnt NBR ISO 14064-1, que traz as especificações e orientações para que as organizações quantifiquem e elaborem os relatórios de emissões e remoções de GEE, a Abnt NBR ISO 14064-2, que contêm as especificações e orientações para elaboração de projetos para quantificação, monitoramento e elaboração de relatórios das reduções de emissões ou da melhoria das remoções de GEE e, finalmente, a Abnt NBR ISO 14064-3, que reúne as diretrizes para o processo relacionado à verificação e validação dos aspectos relativos aos GEE.

Vale destacar que no Brasil também foi disponibilizada a Abnt ISO/TR 14.069, atinente à quantificação e elaboração de relatórios de emissões de GEE para as organizações, com a orientação para aplicar a Abnt NBR ISO 14.064-1. A adoção das normas ISO confere clareza e consistência para a quantificação, o monitoramento, a elaboração do relatório de emissões de GEE, a verificação de inventários e a validação ou a verificação de projetos de GEE. Já, o The Greenhouse Gas Protocol - A Corporate Accounting and Reporting Standard (O protocolo de gases de efeito estufa - Um padrão corporativo de contabilização e reporte), conhecido como $G H G$ Protocol, foi desenvolvido em 1998, e revisado em 2004, nos Estados Unidos pelo World Resources Institute (WRI) para entender, quantificar e gerenciar emissões de GEE (Wbcsd e WRI, 2004).

Em 2008, o Centro de Estudos em Sustentabilidade da Fundação Getúlio Vargas (Gvces) e o WRI, em parceria com o Ministério do Meio Ambiente (MMA), com o Conselho Empresarial Brasileiro para o Desenvolvimento Sustentável (Cebds), o World Business Council for Sustainable Development (Wbscd) e outras empresas, adaptaram o método para o contexto brasileiro. Hoje, é o método mais utilizado no Brasil e no mundo por empresas e governos para elaborar inventários de GEE, sendo compatível com as diretrizes da ISO 14.064 e com os métodos de quantificação do Ipcc. Umas das principais características do GHG Protocol é a sua estrutura para contabilizar os GEE, o seu caráter modular e flexível, além da neutralidade em termos de políticas ou programas, bem como o fato de ser baseada em um amplo processo de consulta pública (Gvces, 2019).

Tanto a ISO 14.064, quanto o GHG Protocol adotam os GEE reconhecidos no Protocolo de Kyoto, a saber: Dióxido de Carbono $\left(\mathrm{CO}_{2}\right)$, Metano $\left(\mathrm{CH}_{4}\right)$, Óxido Nitroso $\left(\mathrm{N}_{2} \mathrm{O}\right)$, Hexafluoreto de 
Thiago Alexsandro Novaes das Virgens, José Célio Silveira Andrade, Sebastián Labella Hidalgo

Enxofre $\left(\mathrm{SF}_{6}\right)$, Hidrofluorcarbonos (HFC) e Perfluorcarbonos (PFC). Igualmente, consideram cinco princípios inspirados, em partes, nos de contabilidade financeira e nos de reporting, a fim de apoiar todos os aspectos relacionados à contabilização e à elaboração de inventários de GEE: Relevância; Abrangência/integridade; Consistência; Transparência e Exatidão.

A ISO 14.064 e o GHG Protocol exigem que as organizações também estabeleçam os seus limites operacionais, classificando as emissões em diretas e indiretas. As diretas são aquelas que pertencem ou são controladas pela organização inventariante, ao passo que as indiretas são geradas em consequência das atividades da organização, mas ocorrem em fontes que não são de sua propriedade ou são controladas por outra organização. As emissões diretas e indiretas são agrupadas em três escopos. No Escopo 1, têm-se as emissões diretas, a exemplo da combustão estacionária e emissões fugitivas. No Escopo 2, estão incluídas as emissões indiretas associadas a geração de eletricidade adquirida e consumida pela organização. Por fim, no Escopo 3 estão concentradas as demais emissões indiretas não vinculadas à eletricidade, tais como: bens e serviços consumidos e deslocamento de funcionários para o trabalho. Os cálculos e reportes dos Escopos 1 e 2 são obrigatórios, tanto na ISO 14064, quanto no GHG Protocol, sendo o Escopo 3 opcional. No entanto, geralmente, as emissões de Escopo 3 quando calculadas representam uma proporção muito significativa nas emissões de GEE de uma organização.

Uma das principais diferenças do GHG Protocol e da ISO 14.064 reside no fato de que a ISO é um padrão internacional verificável, mas que não oferece e nem recomenda ferramentas de cálculo e fatores de emissão específicos. Neste sentido, o Programa Brasileiro GHG Protocol oferece ferramenta de cálculo e fatores de emissão para o contexto brasileiro que, em geral, consideram um algoritmo com dois parâmetros: dado de atividade e fator de emissão. O primeiro é uma medida quantitativa de uma atividade geradora de emissões de GEE, a exemplo da quantidade de litros de combustível consumido por uma organização, ao passo que o fator de emissão considera as emissões oriundas da produção de uma unidade funcional do produto/serviço foco da atividade de interesse, por exemplo: um quilo de $\mathrm{CO}_{2}$ emitido por litro de combustível consumido. Para maior aprofundamento da metodologia e aplicação da ISO 14.064 e do GHG Protocol, têm-se as publicações: Wbcsd e WRI (2004) e Monzoni (2008).

\subsection{MC3 e o BookFeel}

O MC3 foi desenvolvido tendo como base o conceito de Pegada Ecológica, de William Rees e Mathis Wackernagel, sendo publicado pela Asociación Española de Normalización y Certificación (Aenor) nos anos 2000. É um método híbrido por níveis, desenvolvido a partir da combinação de fatores derivados da Análise Input-Output, com fatores da Análise de Processos, cujas emissões são expressas em Dióxido de Carbono Equivalente $\left(\mathrm{CO}_{2} \mathrm{e}\right.$ ) (Álvarez et al., 2014; Pereira et al., 2016). O MC3 atende as diretrizes do Ipcc e demais normas e publicações internacionais, entre elas, o GHG Protocol, ISO 14064 e ISO 14069, permitindo analisar a performance climática das organizações, englobando, de forma completa, as emissões diretas e indiretas de todos os ramos de uma empresa, inclusive dos bens e serviços consumidos (Veiga, 2017). O método em comento foi concebido para ser simples, flexível e transparente, tendo, como um de seus diferenciais, a possibilidade de também calcular a Pegada Ecológica e a PC organizacional e de produto simultaneamente, com o emprego de unidades físicas $\left(\mathrm{Kg}, \mathrm{t}, \mathrm{m}^{3}\right) \mathrm{e}$, quando estas não estão disponíveis, em unidades monetárias (R\$).

Tendo em vista que muitas informações sobre determinados tipos de consumo de uma organização não são expressas ou não estão disponíveis em unidades físicas, mas em despesas financeiras, o MC3 realiza a conversão destas despesas em unidades de massa (toneladas) considerando os preços médios de um produto no período do estudo, por exemplo $\mathrm{R} \$ / \mathrm{kg}$. Adicionalmente, utiliza estatísticas que fornecem informações sobre importações e exportações de diferentes capítulos tarifários, expressas em unidades monetárias e toneladas. Assim, uma vez que a organização conhece os dados do peso dos produtos adquiridos, o MC3 utiliza dados de intensidade

Revista de Gestão Social e Ambiental - RGSA, São Paulo, v. 14, n. 1, p. 74-92, jan./abr. 2020. 
energética, ou pegadas unitárias de produtos e fatores de emissão, para transformar toneladas de produto em emissões de GEE. Isto contribui para que as emissões sejam calculadas mais facilmente e permitem a comparação dos resultados entre empresas (Álvarez et al., 2014; Goyanes, 2014; Veiga, 2017).

Cabe ressaltar que os fatores de intensidade energética indicam a energia consumida na produção de cada um dos produtos consumidos por uma organização, expressa em Gigajoules por tonelada $(\mathrm{GJ} / \mathrm{t})$. O MC3 adota os valores desses fatores dos trabalhos desenvolvidos por Simmons et al. (2006) e Carballo-Penela e Doménech (2010). Com isto, utilizando-se os fatores de emissão de fontes confiáveis, a exemplo do Ipcc, a energia incorporada aos produtos se transforma em emissões de GEE e, posteriormente, em $\mathrm{CO}_{2} \mathrm{e}$, adotando-se o Potencial de Aquecimento Global de cada um dos gases (Goyanes, 2014).

Com base no exposto, o MC3 já é um método validado e um dos mais aceitos na Espanha para quantificar o Escopo 3 no âmbito do Registro Público Espanhol de PC, tendo o suporte do Comitê Técnico da CarbonFeel Initiative, grupo formado por pesquisadores, técnicos e especialistas em PC de diversas universidades espanholas, com parcerias de pesquisadores, universidades, empresas, instituições ao redor do Mundo, inclusive do Brasil (Álvarez et al., 2014; Veiga, 2017). A figura 3 apresenta alguns dos trabalhos publicados sobre o MC3, os quais permitem o alcance de um maior aprofundamento do desenvolvimento metodológico e aplicação do método em discussão. Ademais, têm-se os trabalhos publicados por Pereira et al. (2016); Alvarez et al. (2015); Álvarez e Rubio (2015a); Álvarez e Rubio (2015b); Álvarez et al. (2014); Quezada et al. (2013); Cagiao et al. (2011) e Carballo-Penela e Doménech (2010) e Carballo-Penela et al. (2009).

\begin{tabular}{|c|c|}
\hline Autores & Destaques \\
\hline 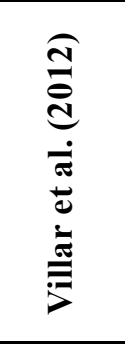 & $\begin{array}{l}\text { Apontaram que o cálculo da PC, } \\
\text { utilizando o MC3, pode ser realizado pelos diferentes fornecedores de bens e } \\
\text { serviços de uma organização, os quais fornecem dados de suas PCs para serem } \\
\text { considerados no cálculo da PC da organização. Isto contribui para uma maior } \\
\text { abrangência e qualidade por ser baseada em dados primários, ou seja, a PC real } \\
\text { de seus fornecedores. Ademais, afirmaram que o custo e o tempo de execução } \\
\text { dos cálculos utilizando o MC3 são acessíveis a qualquer organização. }\end{array}$ \\
\hline 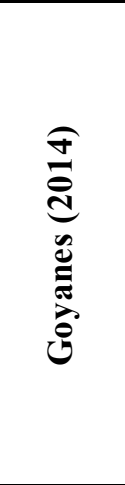 & $\begin{array}{l}\text { - Apontaram diversas vantagens e } \\
\text { algumas limitações do MC3, tais como facilidade de consultar os indicadores e } \\
\text { demais parâmetros inseridos nos cálculos; ser uma metodologia simples e de } \\
\text { fácil utilização; adoção de dados que consideram as despesas financeiras da } \\
\text { organização. Destacou que o indicador PC pode ser desagregado para fornecer } \\
\text { informações parciais que possam ser de interesse da organização. Como } \\
\text { limitação, informou que a maneira de considerar o ciclo de vida de produto se } \\
\text { afasta, em alguns casos, do uso mais consolidado para este tipo de análise, uma } \\
\text { vez que a proposta é menos completa do que uma análise de ciclo de vida } \\
\text { baseada em processos e implica maior agregação. }\end{array}$ \\
\hline
\end{tabular}


Thiago Alexsandro Novaes das Virgens, José Célio Silveira Andrade, Sebastián Labella Hidalgo

\begin{tabular}{|c|c|}
\hline 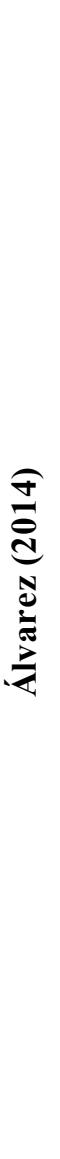 & 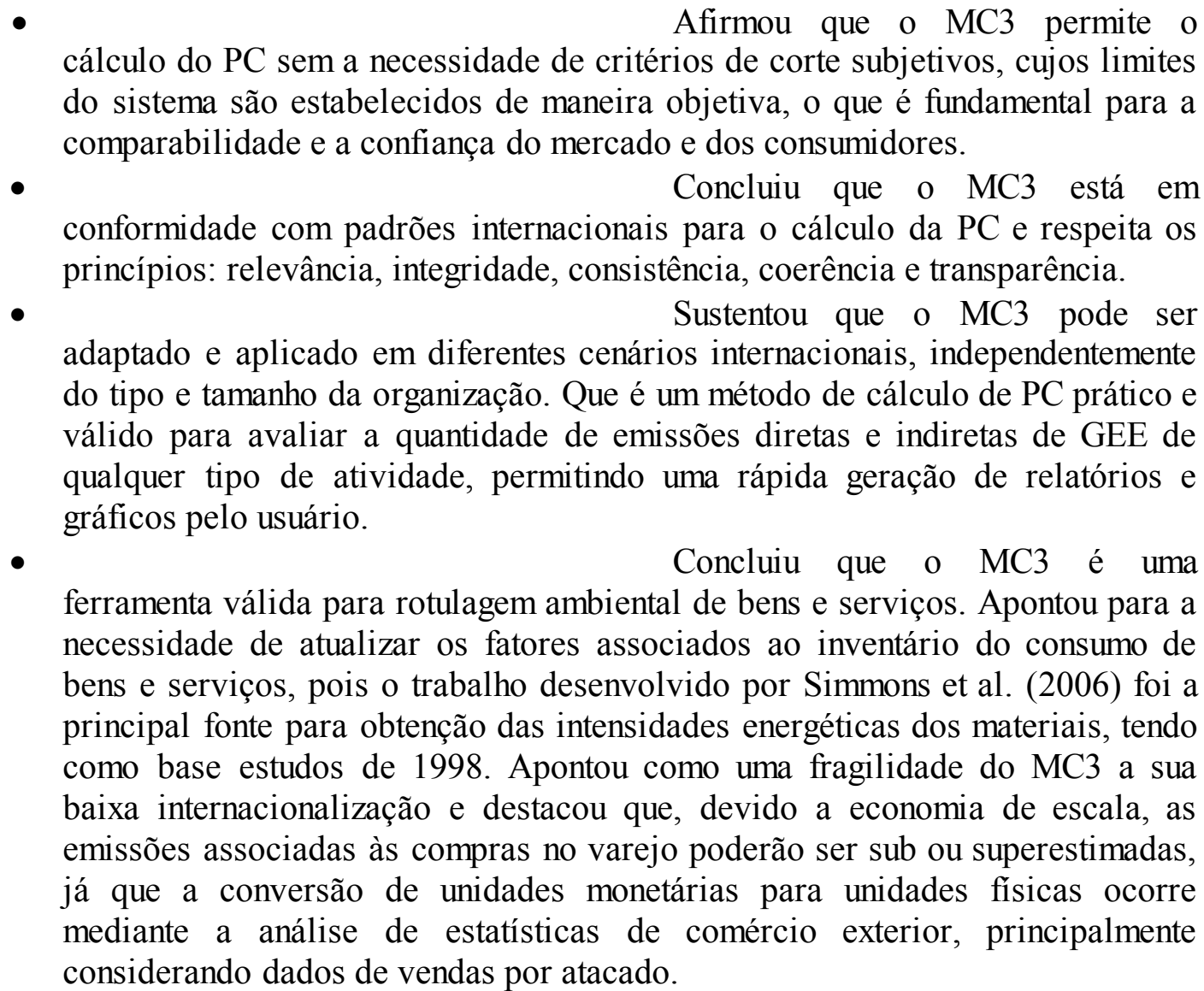 \\
\hline 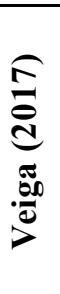 & $\begin{array}{l}\text { - Concluiu que o MC3 calculou de } \\
\text { forma completa e fiel a PC organizacional, abordando todos os capítulos } \\
\text { contidos na ISO 14.069. Igualmente, a utilização do MC3 e o BookFeel foi } \\
\text { importante pela obtenção de informações pormenorizadas acerca das emissões, } \\
\text { permitindo a organização estudar quais as melhores estratégias para reduzir as } \\
\text { emissões de GEE. }\end{array}$ \\
\hline
\end{tabular}

Figura 3. Destaques de trabalhos publicados sobre o MC3

Fonte: Os autores

O MC3, atualmente, dispõe do BookFeel, uma ferramenta de cálculo executada no Microsoft Office Excel, que demanda conexão com a internet e configurável às necessidades do cenário de estudo e adaptável a qualquer metodologia, norma ou protocolo setorial. Portanto, compatível com o GHG Protocol e a Abnt ISO 14.064. Todos os parâmetros de cálculo do BookFeel seguem os princípios da ISO 14.069. Com isso, o BookFeel permite a introdução dos dados de atividades para calcular a totalidade das emissões de GEE emitida, direta ou indiretamente, pela atividade de uma organização, produto, evento, cidade etc. O BookFeel dispõe diversas abas de configuração, como as para inserir os valores dos fatores de emissão, poder calorífico, intensidade energética, dados de atividades (em unidades físicas ou monetárias) e as abas de visualização e reporte dos resultados da PC. Destaca-se que o BookFeel possui o padrão Footprint Electronic Exchange Language (Feel) que permite o intercâmbio eletrônico de informações entre diferentes BookFeel ou demais plataformas, visando a automação dos cálculos colaborativos intra ou interorganizacionais (CarbonFeel, 2016).

\section{MÉTODOS DE PESQUISA}

Este trabalho deriva de um estudo de caso desenvolvido para calcular a PC organizacional de um órgão público brasileiro, tendo 2017 como ano-base. O Ministério Público do Estado da 
Bahia (Mpba) foi escolhido para desenvolver o estudo de caso pelas suas atribuições constitucionais, capilaridade e poder de influência no Estado da Bahia e nos demais entes do ministério público brasileiro, bem como pela facilidade de acesso às informações e pelo conhecimento institucional do autor principal deste trabalho, o qual é servidor efetivo do órgão em comento. A definição do ano-base considerou o ano imediatamente anterior ao de início da pesquisa, cujos dados e informações necessários para a sua execução estavam disponíveis ou em consolidação pelo órgão. Foi adotada a técnica de triangulação de dados para validar os dados obtidos pela pesquisa documental, entrevistas, reuniões, bases de dados e observação participante do autor principal enquanto servidor do Mpba.

Após extensa revisão de literatura nacional e internacional, diante do caráter inovador, do pioneirismo de sua aplicação em órgãos públicos brasileiros, assim como dos benefícios relatados na literatura especializada, em especial, quanto a capacidade de calcular as emissões do Escopo 3, o "BookFeel" foi definido como ferramenta de cálculo. Por fim, a escolha dos princípios e dos escopos para os cálculos considerou as diretrizes do GHG Protocol e da ISO 14.064. Diante do exposto, a seguir, são apresentados e detalhados os cinco passos executados para a consecução dos objetivos da pesquisa.

\subsection{Passo 1: Definição da Unidade de Análise e Ano-base}

Ministério Público do Estado da Bahia (Mpba) e 2017. O Mpba é uma instituição pública permanente, essencial à função jurisdicional do Estado, com dever de defender a ordem jurídica, o regime democrático e os interesses sociais e individuais indisponíveis, assim como fiscalizar o cumprimento das leis, inclusive as ambientais e, para tanto, pode acionar o Poder Judicial. O Mpba está localizado no Estado da Bahia e possui duas sedes na cidade de Salvador, capital do Estado e, em 2017, pelo menos uma unidade física em 252 dos 417 municípios baianos.

\subsection{Passo 2: Seleção do método e ferramenta de quantificação}

Tendo em vista o disposto no item 2.3, o método selecionado para a quantificação da PC foi o MC3, tendo o BookFeel como ferramenta de cálculo na versão 18.1. Como o BookFeel não é uma ferramenta gratuita, para que fosse utilizado neste estudo sem custos, foi firmado um protocolo de parceria acadêmica entre a Iniciativa CarbonFeel e a Escola de Administração da Universidade Federal da Bahia (ufba). Adicionalmente, para planejar, parametrizar e executar a folha de cálculo, foram realizadas quinze webconferências entre 2017 e 2019 e uma reunião presencial com o Diretor de Programa da Iniciativa CarbonFeel, em Barcelona/Espanha. Para que houvesse uma experiência de cálculo e reporte utilizando o BookFeel nas melhores condições, foram utilizados: Sistema Operacional (Windows 10); Memória (8 GB de RAM); Software (Microsoft Excel 2013), com ativação da execução de macros; navegador de Internet (Google Chrome) e conexão com Internet de alta velocidade.

As definições da hierarquia, dos capítulos e fontes de emissão, foram em consonância com a ISO 14.069, adotando-se a abordagem de controle operacional para a definição do limite organizacional, abarcando as unidades cujos controles das políticas operacionais e despesas eram de responsabilidade do Mpba. Outrossim, foram considerados os gases Dióxido de Carbono $\left(\mathrm{CO}_{2}\right)$, Metano $\left(\mathrm{CH}_{4}\right)$ e Óxido Nitroso $\left(\mathrm{N}_{2} \mathrm{O}\right)$, expressos em Dióxido de Carbono Equivalente $\left(\mathrm{CO}_{2} \mathrm{e}\right)$, os demais GEE foram considerados insignificantes, tendo em vista a natureza das atividades desenvolvidas no Mpba.

Nos Escopos 1, 2 e 3 foram contempladas 440 fontes de emissão, sendo 5 do Escopo 1, 1 do Escopo 2 e 434 do Escopo 3. No Escopo 1, foram contabilizados: Combustão Móvel (Combustíveis Fósseis: Gasolina e Diesel) e Biomassa (Biodiesel, Etanol Hidratado e Etanol Anidro), ao passo que no Escopo 2 foi calculada as emissões da eletricidade importada e consumida e, finalmente, no 
Thiago Alexsandro Novaes das Virgens, José Célio Silveira Andrade, Sebastián Labella Hidalgo

Escopo 3, foram contabilizados: Compra de Produtos/ Serviços (Produtos Não-Orgânicos; Produtos de Origem Agrícola, Animal e Pesqueira; Recursos Florestais; Serviços e Contratos: Serviços de baixa mobilidade e Serviços de alta mobilidade; Água); Resíduos Gerados pelas Atividades da Organização (Aterros com recuperação de metano; Aterros sem recuperação de metano e Aterros sem classificação; Tratamento de Efluentes); Viagens a Negócio (Avião e Ônibus de Viagem); Bens Arrendados (Aluguel de áreas industriais, domínio público etc. e Outros: locação de veículos e equipamentos) e Deslocamento de Funcionários (veículos particulares e ônibus)

As emissões de GEE do Escopo 1 advindas de processos industriais, emissões e remoções agrícolas, mudança do uso do solo, tratamento de resíduos e de efluentes foram consideradas inexistentes. Já, as emissões de GEE oriundas das emissões fugitivas dos extintores de incêndios e da combustão estacionária foram consideradas desprezíveis. Também não foram calculadas as emissões do Escopo 2 e parte do Escopo 3 de 138 Promotorias de Justiça situadas em espaços cedidos pelo Tribunal de Justiça da Bahia (Tjba), uma vez que o Mpba realiza, de forma parcial, a gestão de custos dessas unidades. Igualmente, não houve cálculo de remoções dada a inexistência de fontes de sumidouros de GEE. Devido à ausência dos dados e/ou da necessidade de despender demasiado tempo para a coleta e tratamento, não foram calculadas as PCs de alguns produtos comprados/consumidos no ano-base e as relacionadas ao transporte e distribuição de produtos em veículos e instalações que não são de propriedade e nem são operados pelo Mpba, além dos serviços terceirizados de transporte e distribuição (incluindo tanto logística de entrada quanto de saída).

\subsection{Passo 3: Atribuição dos algoritmos, fatores de emissão e parâmetros associados}

Para cada capítulo foi definido um "Algoritmo de Cálculo", para cada um dos tipos de GEE considerados no inventário, os quais são amplamente conhecidos e consolidados para calcular as emissões de GEE. O BookFeel contém uma lista de algoritmos válidos para calcular os capítulos, bem como permite que sejam inseridos novos algoritmos mais específicos para o cenário de estudado. O "Algoritmo de Cálculo" possui um código padrão específico e consiste em fórmulas introduzidas para cada variável existente, a fim de tornar possível o cálculo da PC. Igualmente, foram introduzidos os "Algoritmos de Consumo", utilizados para realizar cálculos prévios nos dados de atividade inseridos, com a finalidade de alterar as unidades de medidas, por exemplo. A figura 4 apresenta os diferentes algoritmos considerados no estudo.

\footnotetext{
Algoritmo P902 - Calcula a PC oriunda da combustão de combustíveis.

Emissões $=E 000 * 0,001 * F 006 * F 009 * F 015 i * F 051 i$

Onde: Emissões $=$ Emissões totais de $\mathrm{CO}_{2} \mathrm{e}$ em toneladas; $\mathrm{E} 000=$ Combustão do carburante em litros (L); 0,001 = Conversão de litros para metros cúbicos $\left(\mathrm{m}^{3}\right)$; F006 $=$ Densidade do Combustível $\left(\mathrm{t} / \mathrm{m}^{3}\right) ; \mathrm{F} 009=$ Poder Calorífico do Combustível $(\mathrm{GJ} / \mathrm{t})$; F015 = Fator de Emissão de Gases por Unidade Energética (t/GJ); F051 = Potencial de Aquecimento Global; i = Gás de Efeito Estufa

Algoritmo P905 - Calcula a PC atinente a aquisição de um produto ou serviço, cujos dados de atividade são toneladas, sendo a intensidade de energia o fator de conversão angular.

\section{Emissões $=E 000 * F 008 * F 015 i * F 051 i$}

Onde: Emissões = Emissões totais de $\mathrm{CO}_{2} \mathrm{e}$ em toneladas; E000 = Consumo (t); F008 = Intensidade Energética $(\mathrm{GJ} / \mathrm{t})$; F015 = Fator de Emissão de Gases por Unidade Energética; F051 = Potencial de Aquecimento Global; i = Gás de Efeito Estufa

Algoritmo P935 - Calcula a PC oriunda da combustão do combustível usado no serviço adquirido e cujos dados de atividade são unidades monetárias.

$$
\text { Emissões }=E 000 * F 006 * F 009 * F 031 * F 015 i * F 051 i * \frac{0,001}{F 003}
$$

Onde: Emissões $=$ Emissões totais de $\mathrm{CO}_{2}$ e em toneladas; $\mathrm{E} 000=$ Consumo $(\mathrm{R} \$) ; 0,001=$ Conversão de litros para metros cúbicos $\left(\mathrm{m}^{3}\right)$; F003 = Preço do combustível em volume $(\mathrm{R} \$ / \mathrm{L}) ; \mathrm{F} 006=$ Densidade do combustível ( $\left.\mathrm{t} / \mathrm{m}^{3}\right)$; F009 = Poder Calorífico do Combustível (GJ/t); F015 = Fator de Emissão de Gases por Unidade Energética (t/GJ); F031 = Participação energética na fatura de serviços (\%); F051 = Potencial de Aquecimento Global; i = Gás de Efeito Estufa
} 
Algoritmo P942 - Calcula a PC provocada pelas emissões nas plantas de tratamento de efluentes e cujos dados de atividade são metros cúbicos de água tratada.

$$
\text { Emissões }=((E 000 * F 127 * 0,000001 *(1-F 016)) *(F 004 * F 017)-F 108) * F 051(2)
$$

Onde: Emissões = Emissões totais de $\mathrm{CO}_{2} \mathrm{e}$ em toneladas $; \mathrm{E} 000=$ Efluentes de entrada e tratados $\left(\mathrm{m}^{3}\right) ; \mathrm{F} 127=$ Demanda Bioquímica de Oxigênio (DBO) ou Demanda Química de Oxigênio (DQO) (mg/l); 0,000001 = Conversão para toneladas; F016 = Fração de $\mathrm{DBO}$ ou DBO eliminada no tratamento primário (Adimensional); F004 = Fator de Correção do Metano (MCF) (Adimensional); F017 = Máxima capacidade de produção de Metano ( $\mathrm{kg} \mathrm{CH}_{4} / \mathrm{kg}$ DBO ou Kg DQO); F108 = Quantidade de metano recuperada por unidade funcional produzida $\left(\mathrm{kgCH}_{4} / \mathrm{UF}\right) ; \mathrm{F} 051(2)=$ Potencial de Aquecimento Global do Metano $\left(\mathrm{tCO}_{2} \mathrm{e} / \mathrm{t}\right)$

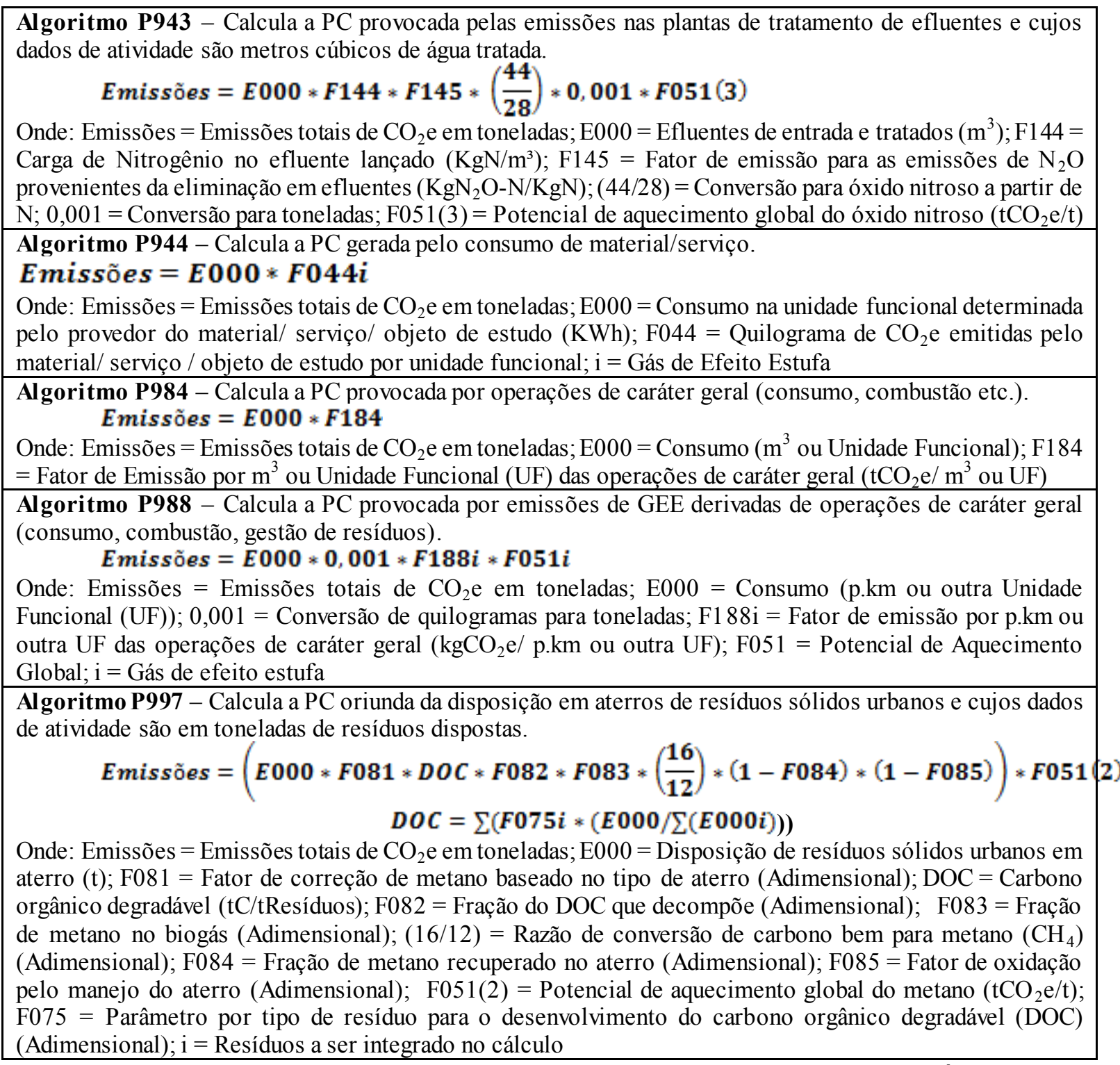

Figura 4. Algoritmos alocados, contendo os tipos de fatores de emissão e parâmetros

Os algoritmos são constituídos de fatores de emissão e outros parâmetros, tais como Preço dos Combustíveis em Volume (F003), Participação Energética na Fatura de Serviços (F031) e Potencial de Aquecimento Global ou Global Warming Potential (GWP) (F051), cujos valores foram obtidos em publicações oficiais. Os Fatores de Emissão (FE) adotados foram os estandardizados, notadamente, os do Programa Brasileiro GHG Protocol por serem mais direcionados às emissões em território brasileiro, com adaptações à realidade nacional. 
Thiago Alexsandro Novaes das Virgens, José Célio Silveira Andrade, Sebastián Labella Hidalgo

\subsection{Passo 4: obtenção, seleção e categorização dos dados de atividades}

O website "Portal da Transparência" do Mpba foi uma das principais fontes de obtenção de dados, o qual disponibiliza dados e informações consolidadas sobre recursos humanos e a execução orçamentária do órgão, com livre acesso ao público em geral. Igualmente, por meio do setor contábil do Mbpa, o detalhamento das despesas e investimentos realizados pelo Mpba foi obtido pelo Sistema Integrado de Planejamento, Contabilidade e Finanças do Estado da Bahia (Fiplan) e do Sistema de Informações Contábeis e Financeiras (Sicof), mantidos pelo Mpba e Governo do Estado da Bahia. Adicionalmente, outros dados foram obtidos diretamente com os fornecedores dos bens e serviços ou via internet, principalmente sobre características dos produtos consumidos, tais como peso, volume etc.

Foram realizadas entrevistas com gerentes e técnicos do Mpba para obter maior detalhamento, dirimir dúvidas e garantir que os dados de atividades considerados no estudo estavam corretos, assim como foram analisados relatórios técnicos, contábeis e gerenciais do órgão. Foi empregada a técnica de triangulação de dados para validação dos dados coletados, com confronto e cruzamento de documentos, bases de dados, informações e entrevistas realizadas com especialistas na temática de estudo e gestores do Mpba, além das observações diretas realizadas pelo autor principal deste artigo.

\subsection{Passo 5: cálculo e avaliação das incertezas da pegada de carbono}

O cálculo da PC ocorreu de forma automatizada após a parametrização do BookFeel. Considerando que o estudo realizado foi baseado unicamente em dados secundários, não foi realizada avaliação das incertezas associadas ao monitoramento contínuo de emissões e à determinação direta de fatores de emissão. Assim, foram avaliadas as incertezas associadas aos parâmetros, tais como dados de atividades e fatores de emissão. Para tanto, adotou-se o método utilizado pelo Waycarbon e International Council for Local Environmental Initiatives (Iclei) na elaboração do inventário da Região Metropolitana de Campinas/São Paulo, avaliando as incertezas a partir de uma abordagem qualitativa, especificamente quanto às incertezas dos dados coletados, considerando três níveis de classificação (Bittencourt et al., 2018):

- Nível de Incerteza Baixo (NIB): Aplicado quando os dados coletados foram obtidos de órgãos públicos gestores de dados nacionais, que não necessitaram de tratamentos prévios. Estes são dados transparentes, rastreáveis e de fontes confiáveis.

- Nível de Incerteza Médio (NIM): Aplicado quando os dados foram obtidos de órgãos públicos gestores de dados nacionais, sendo necessário realizar algum tipo de tratamento ou adotar algum tipo de premissa.

- Nível de Incerteza Alto (NIA): Aplicado quando os dados foram obtidos por múltiplos atores (ex.: grupos focais) e/ou quando foi necessário adotar diversas premissas com base em fontes bibliográficas diversificada não pública.

Em função das dificuldades técnicas, de tempo e de recursos financeiros, não foi realizada uma avaliação quantitativa, a qual foi entendida como uma limitação desta pesquisa. No entanto, foram identificadas as principais limitações do estudo que podem implicar numa maior imprecisão, a fim de apoiar futuros esforços para entender as causas das incertezas e ajudar a identificar maneiras de melhorar a qualidade do cálculo da PC.

\section{RESULTADOS E DISCUSSÃO}

A utilização do BookFeel se mostrou útil e confiável para a execução do cálculo da PC. Apesar das diversas abas de configuração, demonstrou-se uma ferramenta intuitiva, de fácil configuração e manuseio amigável, convergindo com os achados de Álvarez (2014) e Veiga (2017).

Revista de Gestão Social e Ambiental - RGSA, São Paulo, v. 14, n. 1, p. 74-92, jan./abr. 2020. 
Pegada carbono de órgãos públicos: guia de cálculo baseado na aplicação do Bookfeel no ministério público do estado da Bahia/Brasil

Ainda, o BookFeel possibilitou uma visão integrada de todos os capítulos e fontes de emissão numa mesma planilha, bem como permitiu que os resultados fossem analisados a partir de planilhas, tabelas dinâmicas e gráficos gerados automaticamente (Figura 5 e Figura 6).

\begin{tabular}{|c|c|c|c|c|c|c|c|c|c|c|c|c|}
\hline 1001 & Ministerio Público del Estado de Bahía & & & & & & & & 1 & & & \\
\hline \multirow[t]{2}{*}{$\underline{\text { Salir }}$} & \multirow{2}{*}{ 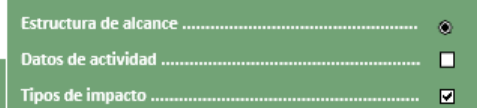 } & \multirow{2}{*}{$\begin{array}{l}0 \\
\square \\
\square\end{array}$} & \multirow{2}{*}{$\begin{array}{l}0 \\
\square \\
\square\end{array}$} & \multirow{2}{*}{$\square$} & \multirow{2}{*}{0} & \multirow{2}{*}{0} & \multirow{2}{*}{$\square$} & & \multicolumn{4}{|l|}{ Datos corporativos } \\
\hline & & & & & & & & & Consumos & & & Tipo de Impacto \\
\hline Codefeel & \multicolumn{7}{|l|}{ Capitulo } & uм & Bookfeel InputFeel & Dióxido de carbono & Metano & Óxido nitroso \\
\hline & \multicolumn{7}{|l|}{ TTOTALES } & & & \begin{tabular}{|r|}
$5.017,8832$ \\
\end{tabular} & 151,3174 & 88,8549 \\
\hline 10200000000 & \multirow{2}{*}{\multicolumn{7}{|c|}{$\begin{array}{l}\text { COMBUSTÁO MÓVEL } \\
\text { COMBUSTIVEIS FÓSSEIS }\end{array}$}} & & & 505,0200 & 2,1793 & 20,0483 \\
\hline 10201000000 & & & & & & & & & & 505,0200 & 2,1598 & 20,0468 \\
\hline 10201010000 & \multicolumn{7}{|l|}{ Gasolina Comercial (contem 2796 de Etanol Anidro) (4.40.3.3.39.06) } & 1 & $250.151,79$ & 408,5908 & 2,1131 & 18,2805 \\
\hline 10201020000 & \multicolumn{7}{|l|}{ Diesel (contem 7\% de Biodiesel) (4.40.3.3.39.06) } & 1 & $39.435,80$ & 96,4291 & 0,0467 & 1,7664 \\
\hline 10201030000 & \multicolumn{7}{|l|}{ Gás Natural Veicular $(4.40 \cdot 3 \cdot 3 \cdot 39.06)$} & $\mathrm{m} 3$ & 0,00 & & & \\
\hline 10202000000 & \multicolumn{7}{|l|}{ BIOMASA } & & & 0,0000 & 0,0195 & 0,0015 \\
\hline 10202010000 & & 1 & 0,00 & & & \\
\hline 10202020000 & \multirow{2}{*}{\multicolumn{7}{|c|}{$\begin{array}{l}\text { Biodiesel (B100) (4.40.3.3.39.06) } \\
\text { Etanol hidratado }\end{array}$}} & i & 0,00 & & & \\
\hline 10202030000 & & & & & & & & $i$ & $9.263,49$ & & 0,0036 & 0,0001 \\
\hline 10202040000 & \multicolumn{7}{|l|}{$\begin{array}{l}\text { Etanoil hidratado } \\
\text { Etanol anidro (27\% do Gasolina Comercial) }\end{array}$} & $\mathrm{i}$ & & & 0,0151 & 0,0009 \\
\hline 10202050000 & \multicolumn{7}{|l|}{ Biodiesel (7\% do Diesel) } & $i$ & & & 0,0009 & 0,0005 \\
\hline 10400000000 & \multicolumn{7}{|l|}{ FUGITVAS } & & & 0,0000 & 0,0000 & 0,0000 \\
\hline 10500000000 & \multicolumn{7}{|l|}{$\begin{array}{l}\text { FUGITIVAS } \\
\text { EMISSOOES DA AGRICULTURA E MUDANÇAS DO SOLO }\end{array}$} & & & 0,0000 & 0,0000 & 0,0000 \\
\hline 20000000000 & \multicolumn{7}{|l|}{ ESCOPO 02 - EMISSOES INDIRETAS POR ENERGIA } & & & 368,5797 & 0,0000 & 0,0000 \\
\hline 20100000000 & \multirow{2}{*}{\multicolumn{7}{|c|}{ ELETRICIDADE IMPORTADA E CONSUMIDA }} & & & 368,5797 & 0,0000 & 0,0000 \\
\hline 20101000000 & & & & & & & & $\mathrm{kWh}$ & $3.976 .048,77$ & 368,5797 & & \\
\hline 30000000000 & \multirow{2}{*}{\multicolumn{7}{|c|}{$\begin{array}{l}\text { ESCOPO } 03 \text { - OUIRAS EMISSOES INDIRETAS } \\
\text { ATIVIDADES RELACIONADAS COM ENERGIA NÃO INCLUÍDAS NAS EMISSÕ̃ES DIRETAS E INDIRETAS POR ENERGIA }\end{array}$}} & & & $4.144,2835$ & 149,1381 & 68,8066 \\
\hline 30100000000 & & & & & & & & & & 0,0000 & 0,0000 & 0,0000 \\
\hline 30103000000 & Perdas na transmissão e distribuição & & & & & & & MWh & 0,00 & & & \\
\hline 30200000000 & COMPRA DE PRODUTOS & & & & & & & & & $2.159,2549$ & 0,2877 & 9,9628 \\
\hline 30201000000 & Materiais não orgânicos & & & & & & & & & 401,4243 & 0,1942 & 7,3532 \\
\hline 30201010000 & Agentes tensoactivos para el lavado y preparación & & & & & & & & & 0,1874 & 0,0001 & 0,0034 \\
\hline 30201010100 & DETERGENTE, liquido, neutro. Embalagem com 5 & & & & & & & UND & 124,00 & 0,1874 & 0,0001 & 0,0034 \\
\hline 30201020000 & Alcoholes, fenoles, alcoholes fenólicos, glicerina & & & & & & & & & 1,6476 & 0,0008 & 0,0302 \\
\hline 30201020100 & ALCOOL, em gel, (embalagem de $500 \mathrm{ml})$. & & & & & & & UND & 635,00 & 0,5644 & 0,0003 & 0,0103 \\
\hline 30201020200 & ALCOOL, etilico, a 96 graus GL Embalagem de 1 litro. & & & & & & & UND & 24,00 & 0,0640 & 0,0000 & 0,0012 \\
\hline 30201020300 & ALCOOL, em gel, embalagem de 1 litro. & & & & & & & UND & 400,00 & 1,0192 & 0,0005 & 0,0187 \\
\hline
\end{tabular}

Figura 5. Captura de tela parcial atinente à aba de resultados do BookFeel Fonte: Os autores

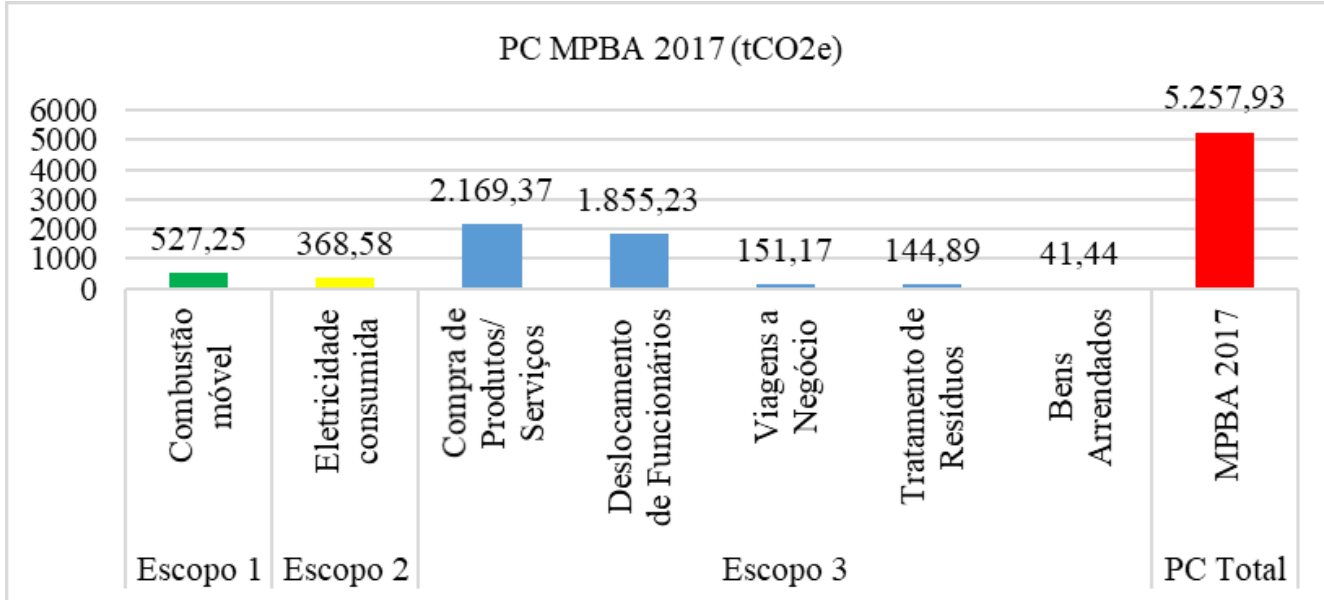

Figura 6. Gráfico (adaptado) gerado pelo BookFeel sobre a PC do MPBA por escopo e capítulos de emissão Fonte: Os autores

Com base no exposto, a visualização dos capítulos e fontes de emissão numa mesma planilha facilitou o acesso, leitura e interpretação dos resultados, contribuindo para uma visão integrada, otimização do tempo e redução dos erros de interpretação atinentes à esta fase. Estes benefícios também foram percebidos com a geração de planilhas, tabelas dinâmicas e gráficos de forma automatizada, pois além de conferir celeridade, contribuíram para uma avaliação pormenorizada da PC, seja por escopo, por gases de efeito estufa, por capítulo de emissão ou, mesmo, por tipo de bem ou serviço consumido, permitindo a organização avaliar as melhores estratégias para redução das emissões de GEE. Estes benefícios são alguns dos diferenciais do BookFeel em relação à ferramenta de cálculo do GHG Protocol (Wbcsd e WRI, 2004) e convergem com os achados de Veiga (2017), Goyanes (2014) e Carballo-Penela et al. (2009). 
Vale destacar que agrupar a enorme quantidade de produtos e serviços consumidos no anobase em subcategorias, de acordo com suas características predominantes, foi uma das etapas que demandou considerável quantidade de tempo, a fim de garantir a aplicação correta dos algoritmos e parâmetros no BookFeel. Somente a categoria "Produtos Não Orgânicos" possuía 57 subcategorias, nas quais foram enquadrados 301 tipos de produtos ou serviços, tais como: equipamentos eletroeletrônicos, sabão, artigos de escritório etc. Assim sendo, foram alocados os fatores de emissão, demais parâmetros e os algoritmos, conforme apresentado na Figura 7, deparando-se com outro diferencial do BookFeel, o "DataBaseFeel", que consiste num banco de dados disponível na ferramenta, que foi utilizado para selecionar os algoritmos e adotar os valores mais apropriados para o cenário estudado.

\section{A000 Panel de configuración estructura de alcance}

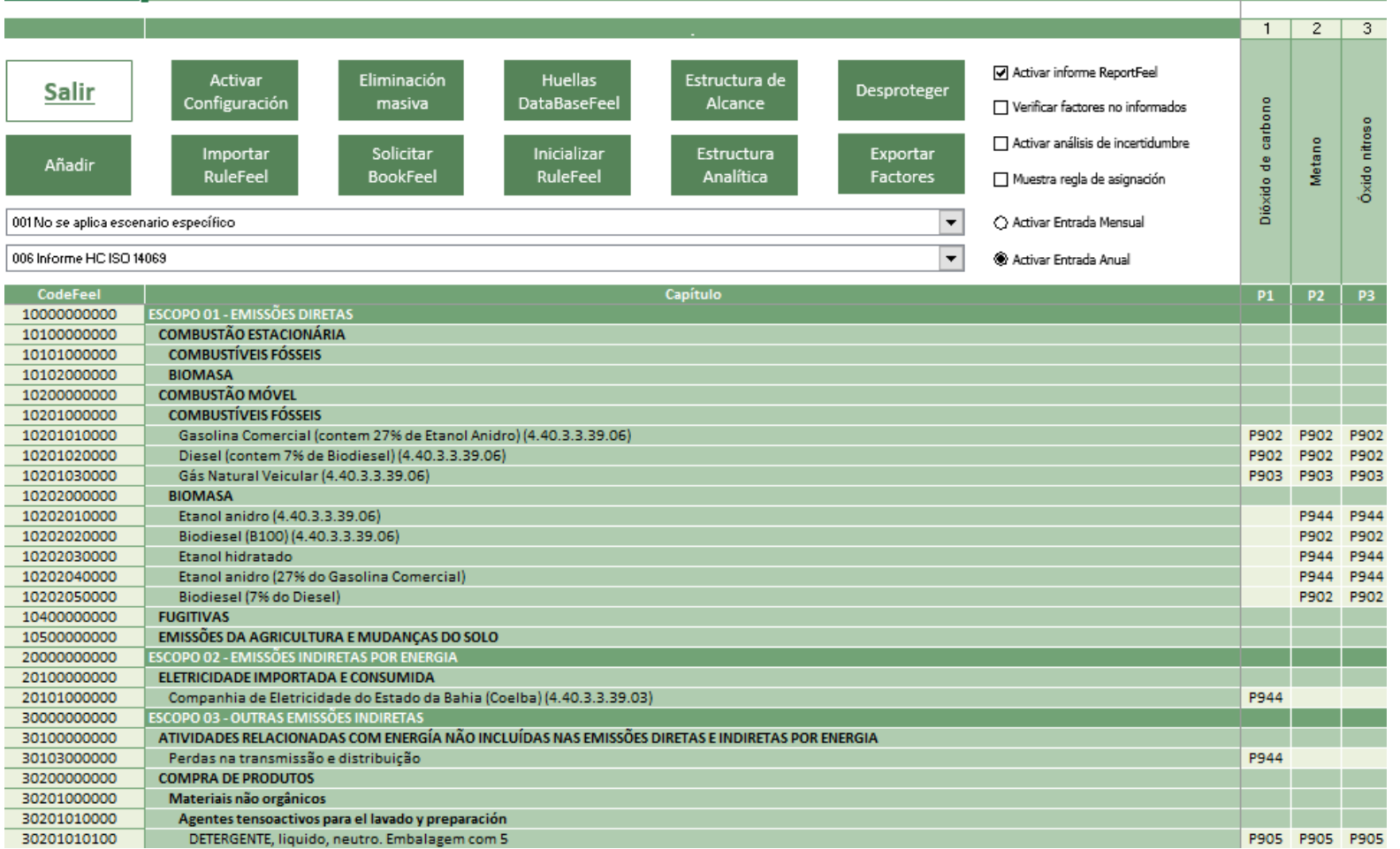

Figura 7. Captura de tela parcial atinente à aba de configuração do BookFeel para alocação dos algoritmos de cálculo Fonte - Os autores

As configurações do Escopo 1 e do Escopo 2 foram mais simples e rápidas no BookFeel, seja pela menor quantidade de fontes de emissão avaliadas ou pelos dados e informações já estarem disponíveis por serem objetos de gestão/controle do órgão ou pela facilidade de obter relatórios de consumo junto ao fornecedor do serviço, caso da concessionária de energia elétrica que disponibilizou relatórios de consumo mensal por unidade consumidora do Mpba. Já a configuração dos capítulos e fontes de Escopo 3 foi mais demorada, pois os algoritmos demandavam dados e informações que, normalmente, os órgãos públicos não gerenciam, a dizer: tipos e quantidade de resíduos e efluentes gerados, moldais de transportes e distâncias percorridas pela força de trabalho, características dos produtos consumidos (peso específico, volume, peso etc.), distâncias percorridas em viagens por tipo de modal utilizado etc. Todos estes dados e informações precisaram ser levantados nos documentos disponíveis ou estimados.

Não obstante ter sido mais complexo e demorado, priorizou-se trabalhar com unidades físicas, ao invés de unidades monetárias, para reduzir as incertezas, uma vez que a utilização de unidades monetárias pode aumentar os riscos de resultados sub ou superestimados, conforme o exposto na figura 8 e os achados de Álvarez (2014). No entanto, foi a introdução das unidades monetárias que viabilizou a execução do cálculo da PC oriunda dos serviços e de bens arrendados 
no ano-base, dada a inexistência de unidades físicas. A depender da realidade e da robustez da gestão realizada por um órgão público, a aplicação de unidades monetárias será ainda mais indispensável e abrangente, visto que nem sempre os órgãos públicos gerenciam o consumo de produtos e serviços com indicadores físicos, mas possuem indicadores financeiros por estar obrigados a prestar contas de todas as suas despesas e investimentos para órgãos de controle e para a sociedade, normalmente, com dados confiáveis. Certamente a possibilidade de inserir unidade monetárias no BookFeel foi um grande diferencial desta ferramenta e da metodologia MC3, em consonância com os estudos de Veiga (2017), Pereira et al. (2016); Álvarez et al. (2015); Álvarez e Rubio (2015a); Álvarez e Rubio (2015b); Álvarez (2014), Goyanes (2014), Quezada et al. (2013), Villar et al. (2012) e Cagiao et al. (2011).

Apesar de não ter sido realizado na execução desta pesquisa, considerando o sustentado por CarbonFeel (2016), o cálculo da PC de determinado órgão público poderá utilizar o BookFeel de forma colaborativa, por meio do padrão "Feel", que permite o intercâmbio eletrônico de informações entre diferentes BookFeels ou outras plataformas. O padrão "Feel" é um importante diferencial em relação a ferramenta de cálculo do GHG Protocol, que, além de contribuir para a redução da ineficiência na fase de inventário por automatizar os cálculos colaborativos intra ou interorganizacionais, pode resultar numa PC com menores custos por estes poderem ser distribuídos entre todos os atores envolvidos na cadeia de suprimentos.

Adicionalmente, contribui para minorar as incertezas, pois são os próprios fornecedores ou as diversas unidades do órgão público que proverão as informações específicas para o cálculo ou calcularão suas próprias PCs utilizando BookFeels específicos integrados ao BookFeel principal para calcular a PC organizacional do órgão público. Tudo isto evita que o cálculo da PC seja baseado em muitos pressupostos, no elevado tratamento de dados e somente em bancos de dados padrão, com redução das incertezas inerentes. Ademais, promove a cultura de reconhecimento e minimização da PC na cadeia de suprimentos pelo chamado "efeito dominó", na qual a responsabilidade pelo $\mathrm{CF}$ é transferida para a cadeia de suprimentos.

Ademais, outro benefício do BookFeel, identificado nesta pesquisa, foi a geração do "GuideFeel”, um relatório de 222 páginas, que foi gerado automaticamente a partir de um comando no BookFeel, contendo todas as etapas de execução do cálculo e todos os dados inseridos para a parametrização da ferramenta. O "GuideFeel", portanto, garantiu a redução de tempo, de custos e incrementou a exatidão, transparência e rastreabilidade dos cálculos realizados, por facilitar o acesso aos dados para análise/verificação por quaisquer partes interessadas. No que se refere as desvantagens do BookFeel, têm-se a obrigatoriedade de estar conectado à internet para utilizar plenamente a ferramenta de cálculo, o que pode ser desafiador em regiões remotas e/ou pobres com indisponibilidade de internet ou com conexão de baixa qualidade, bem como não ser uma ferramenta gratuita e não ser executado em software livre, podendo inviabilizar sua adoção nos órgãos públicos brasileiros com política organizacional de utilizar somente, ou quase que exclusivamente, softwares livres.

Não obstante ser minorado com a utilização do "DataBaseFeel", a configuração do BookFeel pode ser mais extensa e mais demorada comparativamente às planilhas do GHG Protocol, seja em função do maior número de fontes que serão avaliadas seja pela necessidade de selecionar ou desenvolver os algoritmos e parâmetros específicos para os cálculos. Outrossim, têm-se as fragilidades apresentadas por Álvarez (2014) concernentes à pouca internalização da metodologia e da ferramenta de cálculo e a necessidade de melhorar/ atualizar os fatores associados ao inventário do consumo de bens e serviços, cujo estudo base foi publicado há mais de 13 anos por Simmons et al (2006).

Quanto a validade do cálculo da PC executado nesta pesquisa, entende-se que ela foi assegurada pela parametrização do BookFeel estar em consonância com a ISO 14.069, bem como por terem sido empregados fatores de emissão extraídos de referências consistentes com as Diretrizes do Ipcc, com os inventários nacionais do Brasil, com os adotados pelo Programa 
Thiago Alexsandro Novaes das Virgens, José Célio Silveira Andrade, Sebastián Labella Hidalgo

Brasileiro GHG Protocol e pela Iniciativa CarbonFeel. Desta forma, os fatores de emissão foram provenientes de fontes confiáveis e rastreáveis, garantindo a consistência e transparência do cálculo da PC realizado, convergindo com os estudos de Veiga (2017). Como neste estudo não houve medição direta, logo não ocorreram incertezas atinentes às técnicas de medição utilizadas. Outrossim, todos os dados considerados nos cálculos foram analisados criticamente para evitar contagens duplas, omissões ou outras inconsistências.

Quanto aos demais parâmetros e dados de atividades, as incertezas também foram reduzidas ao empregar valores baseados em fontes oficiais do governo brasileiro, em relatórios gerenciais do Mpba, resultando numa ferramenta de cálculo alinhada com os princípios da exatidão e transparência, também observados no estudo de Álvarez (2014). Vale destacar que os parâmetros do MC3, considerados no estudo, já foram validados internacionalmente, sobretudo, na Espanha, conforme sustentado por Álvarez e Rubio (2015b) e Veiga (2017). Considerando a máxima que a análise das incertezas não tem como objetivo questionar a validade das estimativas do cálculo, mas ajudar na priorização dos esforços para melhorar a precisão dos inventários no futuro e orientar as decisões sobre a escolha da metodologia, a figura 8 apresenta a classificação das incertezas associadas aos dados coletados.

\begin{tabular}{|c|c|c|c|c|c|}
\hline Grupo de fontes de emissão & $\begin{array}{c}\text { Fonte } \\
\text { pública }\end{array}$ & $\begin{array}{l}\text { Tratamento } \\
\text { / Premissa }\end{array}$ & $\begin{array}{c}\text { Múltiplos } \\
\text { atores }\end{array}$ & $\begin{array}{c}\text { Fontes } \\
\text { diversas }\end{array}$ & $\begin{array}{l}\text { Nível de } \\
\text { incerteza }\end{array}$ \\
\hline \multicolumn{6}{|l|}{ Escopo 1} \\
\hline Combustão móvel & Sim & Não & Não & Não & BAIXO \\
\hline \multicolumn{6}{|l|}{ Escopo 2} \\
\hline Eletricidade & Sim & Não & Não & Não & BAIXO \\
\hline \multicolumn{6}{|l|}{ Escopo 3} \\
\hline Compra de produtos/ Serviços & Sim & Sim & Não & Não & MÉDIO \\
\hline Deslocamento de funcionários & Sim & Sim & Sim & Sim & ALTO \\
\hline Viagens a negócio & Sim & Sim & Não & Não & MÉDIO \\
\hline Resíduos gerados & Sim & Sim & Sim & Sim & ALTO \\
\hline Bens arrendados & Sim & Sim & Não & Não & MÉDIO \\
\hline
\end{tabular}

Figura 8. Níveis de incerteza por grupos de fontes de emissão

Fonte: Os autores

Constata-se que a incerteza foi baixa nos Escopos 1 e 2, uma vez que os dados de atividades são geridos pelo próprio órgão e, quanto ao Escopo 2, foram fornecidos pela concessionária de energia, cujas entradas foram dadas em unidades físicas, sem necessidade de tratamento, com algoritmos e parâmetros altamente validados e consolidados internacionalmente. No escopo 3, destacam-se as altas incertezas do "Deslocamento de Funcionários" e "Resíduos Gerados", em função da ausência de informações detalhadas, sendo necessário estimar e adotar pressupostos para viabilizar a execução dos cálculos. Com base no exposto, o MC3 e o BookFeel estão em conformidade com os principais padrões internacionais para o cálculo da PC organizacional, em consonância com os princípios de relevância, integridade, consistência, coerência e transparência, cujos resultados convergem com os achados nas pesquisas elencadas na figura 9, especialmente, os de Goyanes (2014), Álvarez (2014) e Veiga (2017).

\section{CONSIDERAÇÕES FINAIS}

Os resultados deste trabalho constataram que o MC3 e a ferramenta de cálculo BookFeel são válidos, fácil de usar e capazes de calcular a PC organizacional, em consonância com as diretrizes do Ipcc, do GHG Protocol e ISO 14064, respeitando os princípios de relevância, integridade, consistência, coerência e transparência, ratificando os achados de pesquisas realizadas. A utilização do BookFeel apresentou diversas vantagens em comparação às planilhas do GHG Protocol, tais como visão integrada dos escopos, capítulos e fontes de emissões inventariadas numa mesma

Revista de Gestão Social e Ambiental - RGSA, São Paulo, v. 14, n. 1, p. 74-92, jan./abr. 2020. 
planilha; geração de gráficos e tabelas dinâmicas na própria ferramenta; rastreabilidade de informações; possibilidade de calcular a PC de forma colaborativa; geração de relatório com todas as etapas de cálculo e, principalmente, a possibilidade de inserir unidades monetárias na ferramenta de cálculo, o que pode ser a única alternativa viável para calcular a $\mathrm{PC}$ em organizações que não dispõem de informações sobre o consumo de bens e serviços expressos em unidades físicas, mas que controlam os investimentos e despesas realizados em unidades monetárias.

Embora já tenham sido validados na Espanha, este trabalho foi pioneiro por validar o MC3 e o BookFeel para o contexto brasileiro, contribuindo para adaptação para outras realidades e, portanto, para a necessária internalização. Constatou-se que, no órgão público avaliado, a aplicação do MC3 e do BookFeel permitiram o cálculo da PC de forma simples e flexível, com uma ampla as emissões de Escopo 3, inclusive do consumo de bens e serviços. Todos os benefícios aqui expostos poderão ser estendidos para outros órgãos públicos e organizações, notadamente, os latinoamericanos, seguindo os cinco passos metodológicos descritos e o guia elaborado nesta pesquisa.

Por fim, entende-se que o MC3 e o BookFeel possibilitam analisar a performance climática das organizações, ação essencial para o enfrentamento das mudanças do clima e para a transição para uma economia de baixo carbono. A pesquisa realizada preencheu e contribuirá para preencher parte da lacuna existente, já que a maior parte das pesquisas realizadas sobre PC abarca organizações privadas, sendo a primeira vez que um trabalho se esforçou para propor um guia para calcular a PC de órgãos públicos, com uma abordagem baseada no consumo, utilizando o MC3 e o BookFeel, que se demonstrou uma excelente alternativa às planilhas do GHG Protocol. Para trabalhos futuros, recomenda-se identificar estratégias para calcular e minorar as incertezas associadas aos métodos, algoritmos, dados de consumo, fatores de emissão e demais parâmetros, bem como identificar estratégias de gestão da PC em órgãos públicos, adotando-se ações de Produção mais Limpa, a fim de reduzir as emissões de GEE, atrelado ao aumento da ecoeficiência e redução de custos.

\section{REFERÊNCIAS}

Abdullah, S., Mansor, A.A., Ahmed, A.N., Napi, N.N.L.M., Ismail, M., 2019. Carbon footprint assessment for academic institution: a UI greenmetric approach. Int. J. Sci. Technol. Res. 8, 17521755.

Álvarez, S., 2014. Huella de carbono de organización y producto con enfoque híbrido: mejoras en el método compuesto de las cuentas contables. Universidad Politécnica de Madrid - Escuela Técnica Superior de Ingeniería de Montes, Forestal y del Medio Natural.

Álvarez, S., Blanquer, M., Rubio, A., 2014. Carbon footprint using the compound method based on financial accounts. the case of the school of forestry engineering, Technical University of Madrid. $J$. Clean. Prod. 66, 224-232.

Álvarez, S., Rubio, A., 2015a. Carbon footprint in green public procurement: a case study in the services sector. J. Clean. Prod. 93, 159-166.

Álvarez, S., Rubio, A., 2015b. Compound method based on financial accounts versus process-based analysis in product carbon footprint: a comparison using wood pallets. Ecol. Indic. 49, 88-94.

Álvarez, S., Sosa, M., Rubio, A., 2015. Product and corporate carbon footprint using the compound method based on financial accounts. The case of Osorio wind farms. Appl. Energy 139, 196-204.

Álvarez, S., Tobarra, M.A., Zafrilla, J.E., 2019. Corporate and product carbon footprint under compound hybrid analysis: application to a spanish timber company. J. Ind. Ecol. 23, 496-507. 
Andrade, J.C.S., Dameno, A., Pérez, J., de Andrés Almeida, J.M., Lumbreras, J., (2018).

Implementing city-level carbon accounting: a comparison between Madrid and London. J. Clean. Prod. 172, 795-804.

ANP (2018). Série histórica do levantamento de preços e de margens de comercialização de combustíveis.

Arellano-wences, H.J., Sampedro-rosas, M.L., Cabrera-cruz, R., Juárez-lópez, A.L., (2015). Generación de emisiones de gases efecto invernadero en unidades académicas de la Universidad Autónoma de Guerrero 0-7.

Barrett, J., Peters, G., Wiedmann, T., Scott, K., Lenzen, M., Roelich, K., Le Quéré, C.(2013). Consumption-based GHG emission accounting: a UK case study. Clim. Policy 13, 451-470.

Bittencourt, F., Brito, M., Mello, A., Dias, B., Salina, F., Albuquerque, I., Chabar, C., Coluna, I.(2018). Cálculo das Emissões de Gases de Efeito Estufa ( GEE) da Região Metropolitana de Campinas. Campinas.

Brasil (2016). Terceira Comunicação Nacional do Brasil à Convenção-Quadro das Nações Unidas sobre Mudança do Clima. Brasilia. Recuperado em: 10 març.2020, de https://doi.org/http://sirene.mcti.gov.br/documents/1686653/1706739/Volume+3.pdf/355d4a1e9f3c-474a-982e-b4a63312813b.

Cagiao, J., Gómez, B., Doménech, J.L., Mainar, S.G., Lanza, H.G.(2011. Calculation of the corporate carbon footprint of the cement industry by the application of MC3 methodology. Ecol. Indic. 11, 1526-1540.

Carballo-Penela, A., Doménech, J.L., 2010. Managing the carbon footprint of products: The contribution of the method composed of financial statements (MC3). Int. J. Life Cycle Assess. 15, 962-969.

Carballo-Penela, A., García-Negro, M. do C., Quesada, J.L.D.(2009). A methodological proposal for corporate carbon footprint and its application to a wine-producing company in Galicia, Spain. Sustainability 1, 302-318.

CarbonFeel (2016). Módulo 9: BookFeel. Manual de Usuário.

Chen, G., Wiedmann, T., Wang, Y., Hadjikakou, M.(2016). Transnational city carbon footprint networks - Exploring carbon links between Australian and Chinese cities. Appl. Energy, 184, 10821092.

Correa, J.P., Montalvo-navarrete, J.M., Hidalgo-salazar, M.A., 2019. Carbon footprint considerations for biocomposite materials for sustainable products : a review. J. Clean. Prod. 208, 785-794.

CPS, (Crown Prosecution Service), 2018. Crown prosecution service annual report and accounts. London.

Defra (2016) Greenhouse gas reporting - Conversion factors 2016.

DPF (2017). Inventário de emissões de gases de efeito estufa metrô. Brasilia.

EPE(2017). Balanço Energético Nacional 2017. EPE 296 p. https://doi.org/620.9:553.04(81).

European Commission, 2004. 2004/156/EC. Off. J. Eur. Union.

Faria, J.A., Andrade, J.C.S., Silva Gomes, S.M.(2018). The determinants mostly disclosed by companies that are members of the carbon disclosure project. Mitig. Adapt. Strateg. Glob. Chang. $23,995-1018$. 
Pegada carbono de órgãos públicos: guia de cálculo baseado na aplicação do Bookfeel no ministério público do estado da Bahia/Brasil

Fry, J., Lenzen, M., Jin, Y., Wakiyama, T., Baynes, T., Wiedmann, T., Malik, A., Chen, G., Wang, Y., Geschke, A., Schandl, H. (2018). Assessing carbon footprints of cities under limited information. J. Clean. Prod. 176, 1254-1270.

GHG Protocol(2018). Ferramenta GHG Protocol versão 2018. Recuperado em 10 março 2020, de: https://doi.org/http://ferramenta.ghgprotocolbrasil.com.br/index.php?r=site/ferramenta.

Goyanes, J.C.(2014). Diseño y validación de un procedimiento de cálculo de la huella de carbono en una administración local 290.

Gui, F., Ren, S., Zhao, Y., Zhou, J., Xie, Z., Xu, C.(2019). Activity-based allocation and optimization for carbon footprint and cost in product lifecycle. J. Clean. Prod. 236, 117627.

Gvces(2019). O Programa Brasileiro GHG Protocol.

Herrero, L.M.J., Leiva, J.L. de la C., Peneda, A.C., Domench, J.L., 2011. Enfoques metodológicos para el cálculo de la Huella de Carbono, Observatorio de la sostenibilidad en España.

Hoekstra, A.Y., Wiedmann, T.O.(2014). Humanity's unsustainable environmental footprint. Science, 80(344), 1114-1117.

Huang, J., Mendoza, B., Daniel, J.S., Nielsen, C.J., Rotstayn, L., Wild, O.(2013). Anthropogenic and natural radiative forcing, in: intergovernmental panel on climate change (Org.), Climate Change 2013 - The Physical Science Basis. Cambridge University Press, Cambridge, p. 659-740.

Ipcc (2006a). Chapter 6: Wastewater Treatment and Discharge, 2006 IPCC Guidelines for National Greenhouse Gas Inventories, 5 Waste.

Ipcc (2006b). Chapter 3: Solid Waste Disposal. 2006 IPCC Guidel. Natl. Greenh. Gas Invent. 4, 6.1-6.49.

Ipcc (2000). Chapter 5: Waste, IPCC Good Practice Guidance and Uncertainty Management in National Greenhouse Gase Inventories.

ISO, 2006. ISO 14064-1:2006 Greenhouse gases -- Part 1: Specification with guidance at the organization level for quantification and reporting of greenhouse gas emissions and removals.

Larsen, H.N., Pettersen, J., Solli, C., Hertwich, E.G.(2013). Investigating the Carbon Footprint of a University - The case of NTNU. J. Clean. Prod. 48, 39-47.

Lima, C.E.P., Ligoski, G.R., Guedes, Í.R.M., Fontenelle, M.R., Silva, J.(2014). Inventário corporativo de emissões atmosféricas de gases de efeito estufa da Embrapa Hortaliças para o ano de 2012. Brasilia.

Lombardi, M., Laiola, E., Tricase, C., Rana, R.(2018). Toward urban environmental sustainability: the carbon footprint of Foggia's municipality. J. Clean. Prod. 186, 534-543.

López, L.-A., Cadarso, M.-Á., Zafrilla, J., Arce, G.(2019). The carbon footprint of the U.S. multinationals' foreign af fi liates. Nat. Commun. 10, 1-11.

Markolf, S.A., Matthews, H.S., Azevedo, I.L., Hendrickson, C.(2017). An integrated approach for estimating greenhouse gas emissions from 100 U.S. metropolitan areas. Environ. Res. Lett. 12.

Mctic (2019). Fator médio - Inventários corporativos. Brasília.

Miehe, R., Scheumann, R., Jones, C.M., Kammen, D.M., Finkbeiner, M.(2016). Regional carbon footprints of households: a German case study. Environ. Dev. Sustain. 18, 577-591.

Miteco, (Ministerio para la Transición Ecológica)(2018). Huella de Carbono 2016 - Ministerio de Agricultura y Pesca, Alimentación y Medio Ambiente (Mapama). Madrid. 
Ozawa-Meida, L., Brockway, P., Letten, K., Davies, J., Fleming, P.(2013). Measuring carbon performance in a UK University through a consumption-based carbon footprint: de Montfort University case study. J. Clean. Prod. 56, 185-198.

Penz, E., Polsa, P. (2018). How do companies reduce their carbon footprint and how do they communicate these measures to stakeholders? J. Clean. Prod. 195, 1125-1138.

Pereira, A., Carballo-Penela, A., González-López, M., Vence, X.(2016). A case study of servicizing in the farming-livestock sector: organisational change and potential environmental improvement. $J$. Clean. Prod. 124, 84-93.

Peters, G.P.(2010). Carbon footprints and embodied carbon at multiple scales. Curr. Opin. Environ. Sustain. 2, 245-250.

Quezada, R., Hsieh, T., Valderrama, J.O.(2013). Determinación de la huella del carbono mediante el método compuesto de las cuentas contables (MC3) para una empresa vitivinícola en Chile. Inf. Tecnol. 24, 3-14.

Robinson, O.J., Tewkesbury, A., Kemp, S., Williams, I.D.(2018). Towards a universal carbon footprint standard: a case study of carbon management at universities. J. Clean. Prod. 172, 44354455.

Santa Catarina (2012). Inventário de Emissões de Gases de Efeito Estufa.

Santos, J.O., Andrade, J.C.S., Marinho, M.M.O., Noyola, A., Güereca, L.P.(2015). Greenhouse gas inventory of a state water and wastewater utility in Northeast Brazil. J. Clean. Prod. 104, 168-176.

Schaltegger, S., Csutora, M.(2012). Carbon accounting for sustainability and management. Status quo and challenges. J. Clean. Prod. 36, 1-16.

Simmons, C., Gonzalez, I., Lewis, K., GFN, M.W.(2006). Methodology for determining global sectoral material consumption, carbon dioxide emissions and Ecological Footprints, One Planet Business.

Vásquez, L., Iriarte, A., Almeida, M., Villalobos, P.(2015). Evaluation of greenhouse gas emissions and proposals for their reduction at a university campus in Chile. J. Clean. Prod. 108, 924-930.

Veiga, B.M.S.(2017). Pegada de carbono empresarial - uma aplicação do método MC3 à Domingos da Silva Teixeira SA. Universidade do Minho.

Villar, J.C., Hidalgo, S.L., Penela, A.C., Meijide, B.G.(2012). Global Warming - Impacts and future perspectives, global warming-impacts and future perspective. InTech.

Virgens, T.A.N. das, Andrade, J.C.S., Hidalgo, S.L.(2020). Carbon footprint of public agencies: the case of Brazilian prosecution service. J. Clean. Prod. 251, 119551.

Wbcsd, WRI (2004). Protocolo de gases com efeito de estufa. Lisboa.

Wiedmann, T., Barrett, J.(2011). A greenhouse gas footprint analysis of UK Central Government, 1990-2008. Environ. Sci. Policy 14, 1041-1051.

RGSA adota a Licença de Atribuição CC BY do Creative Commons (https://creativecommons.org/licenses/by/4.0/). 